\title{
Sem abrigo, o sonho
}

\author{
Maria Helena Serôdio
}

Em tempos de dificil respiração cultural e continuada desvalorização da arte entre nós - por razões económicas impostas e por um fraco investimento na educação pela (e para a) arte -, é de destacar o "sonho sem abrigo"1 que parece mover a obstinada criação cénica a que se devotam ainda muitos artistas portugueses.

Tiveram, todavia, alguns deles, recentemente, uma mais clara projecção internacional: refiro-me ao Prémio Novas Realidades que, no contexto do Prémio Europa de Teatro, celebrado este ano em São Petersburgo, foi atribuído ao Teatro Meridional (e de que nos dá conta aqui Rita Martins numa das "noticias de fora"), bem como à presença d'O Bando na Quadrienal de Praga, como representação oficial portuguesa nesse importante evento artístico mundial. Nesta sua 12. a edição, de 16 a 26 de Junho, foi o "espaço e design da performance" que se assinalou e, nesse contexto, 0 Bando montou a exposição tripartida "Do outro lado", pensada e arquitectada por João Brites e Rui Francisco, e que se desdobrou em três intervenções, cada uma em diferentes lugares da capital checa: "De costas", uma instalação de rua no centro histórico, "De cima", uma intervenção de arquitectura na Igreja de Santa Ana, "De dentro", obra penetrável, uma performance expositiva no Grande Hall do Palácio Veletrzni. 0 catálogo, que se publicou para a ocasião, é, sem dúvida, um importante documento de reflexão teórica e crítica, para além de ser graficamente um objecto notável.

É também uma idêntica disponibilidade para fazer convergir criação artística e reflexão crítica que suscita a continuidade do projecto desta nossa revista Sinais de cena. $E$, na rarefacção que se vem registando quer no espaço que os jornais dedicam ao teatro, quer no contínuo recuo de publicações especializadas em teatro (com o desaparecimento, ano após ano, das poucas que ainda subsistiam), manter uma revista como esta é um acto de resistência cultural que, todavia, queremos que seja um esforço exigente e de qualidade. Para isso temos, felizmente, contado com colaboradores que, generosamente, nos oferecem o seu trabalho - de fotografia, escrita, revisão de textos - e com alguns apoios que nos são vitais: quer os que as companhias, artistas e o Museu Nacional do Teatro nos prodigalizam (para completarmos informação ou incluir imagens), quer os que aceitam publicitar aqui a sua actividade, como é neste número o caso do Teatro Nacional D. Maria II, o Teatro Nacional São João e a Sociedade Portuguesa de Autores, quer ainda o compromisso de aquisição de alguns exemplares como acontece com o Instituto Camões.
Dos conteúdos deste número gostaria de destacar no "Dossiê temático" - as declarações que justificam o Prémio da Crítica que o júri da APCT atribuiu ao Festival Internacional de Marionetas e Formas Animadas (FIMFA) e a João Paulo Seara Cardoso (o brilhante criador do Teatro das Marionetas do Porto), e a que se acrescentam as razões que moveram o mesmo júri a atribuir Menções Especiais a Miguel Guilherme (pela sua interpretação em 0 senhor Puntila e o seu criado Matti), ao elenco d'As Boas Raparigas (no espectáculo Mulheres profundas/Animais superficiais) e a Luís Castro / Karnart pela recriação do universo de Raúl Brandão em Húmus.

De espectáculos ainda se fala na secção "Passos em volta", invocando A Cacatua Verde (do Teatro da Cornucópia e TNDMII), Exactamente Antunes (do TNSJ), O jogador (SLTM - São Luiz Teatro Municipal), Pedro e Inês (d'O Bando em co-produção com múltiplos teatros por onde peregrinou o espectáculo), As três irmãs (TNDMII e Ao Cabo Teatro) e A casa da força (de Angelica Liddell).

Mas na reflexão em torno do espectáculo cabem neste número curiosas transversalidades: as que reportam a cena ao texto literário, como se faz no "Arquivo solto" em torno das traduções do francês no séc. XIX para a colecção Archivo theatral, as que o declinam na relação com as páginas electrónicas de JAR (na secção "Em rede"), ou ainda as que na secção "Leituras" permitem recordar o que em teatro se publicou em Portugal em 2010. Nesta secção cabe, de facto, o elenco de publicações que, com obstinado e exemplar esforço, Sebastiana Fadda anualmente regista, mas também a referência à colecção de peças que o TNDMII vem publicando - com timing e qualidade notáveis - a acompanhar as suas produções, e a referência a um estudo sobre a teoria do dramático.

Nos "Estudos aplicados" é ainda a força dos textos para teatro - ainda que em sobressaltos de novas modalizacões - que se recenseiam, quer na teorização dramatúrgica e cénica (pela voz de Jean-Pierre Sarrazac e Bruno Tackels), quer no Encontro que teve no São Luiz morada mobilizadora no final do ano passado, quer ainda na evocação de um drama poético que Ana Luísa Amaral teceu em torno de Próspero / Paulo Eduardo Carvalho.

Outras transversalidades são ainda invocadas na secção "Notícias de fora": as que a "genética teatral" procura recolher no seu campo especifico de investigação, as que cruzam a linguagem gestual no trabalho do actor rapsodo, e as que atravessam a captação fotográfica de ballet clássico.

Mas é no "Portefólio" que se oferece um conjunto maior de imagens, correspondendo a uma "oficina de fotografia de cena", conduzida por Pedro Soares, e que o Centro de
"Expressão "roubada" a Manuel Gusmão - e aqui descontextualizada - de Migrações de fogo (Lisboa, Caminho, 2004, p. 17). 

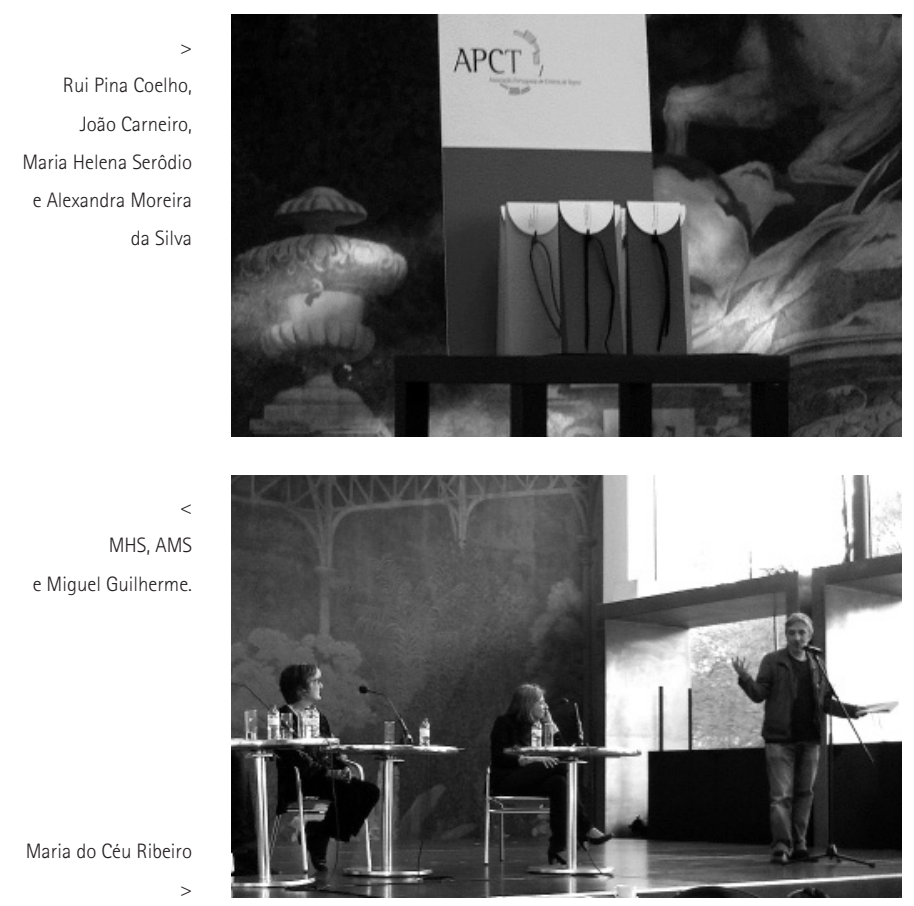

RPC, JC, MHS, AM S e Luis Castro.

Isabel Barros, JC, RPC e MHS

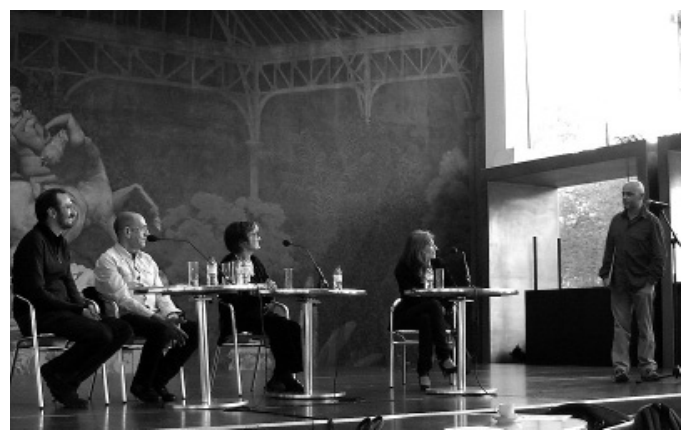

Estudos de Teatro promoveu no contexto do colóquio "Imagens de uma ausência: Modos de (re)conhecimento do teatro através da imagem". Nosso parceiro na produção desta revista, o CET desenvolveu este projecto, reforçando assim a perspectivação plural que os Estudos de Teatro no seu âmbito vêm propondo. E nessa pluralidade cabe também a reflexão sobre gestão cultural que neste número da Sinais de cena nos fez entrevistar José Luis Ferreira, o novo Director do São Luiz Teatro Municipal que, em conversa com João Carneiro e Alexandra Moreira da Silva, nos revela as suas ideias sobre o teatro a cuja direcção chegou através de um concurso público.

E foi no Jardim de Inverno desse teatro que em Março, uma vez mais, decorreu a cerimónia da entrega do Prémio da Crítica, bem como antes se tinham realizado - nos seus vários lugares, que não só em palcos - os Encontros das Novas Dramaturgias Contemporâneas e, mais recentemente - coincidindo com a cerimónia do Prémio da Crítica - se ofereceu ao público lisboeta um Ciclo de teatro do Porto. Pensado por Jorge Salavisa (com a cumplicidade de Isabe Alves Costa), este ciclo revelava a sua vontade de "trazer mostrar e contaminar" Lisboa com o teatro que vinha do Norte. Comissariada por João Pedro Vaz (actual Director Artístico das Comédias do Minho), esta foi uma operação inusitada que trouxe a Lisboa, entre 18 de Fevereiro e 27 de Março, companhias das mais "históricas" às mais recentes e alternativas. Com o título genérico "De António
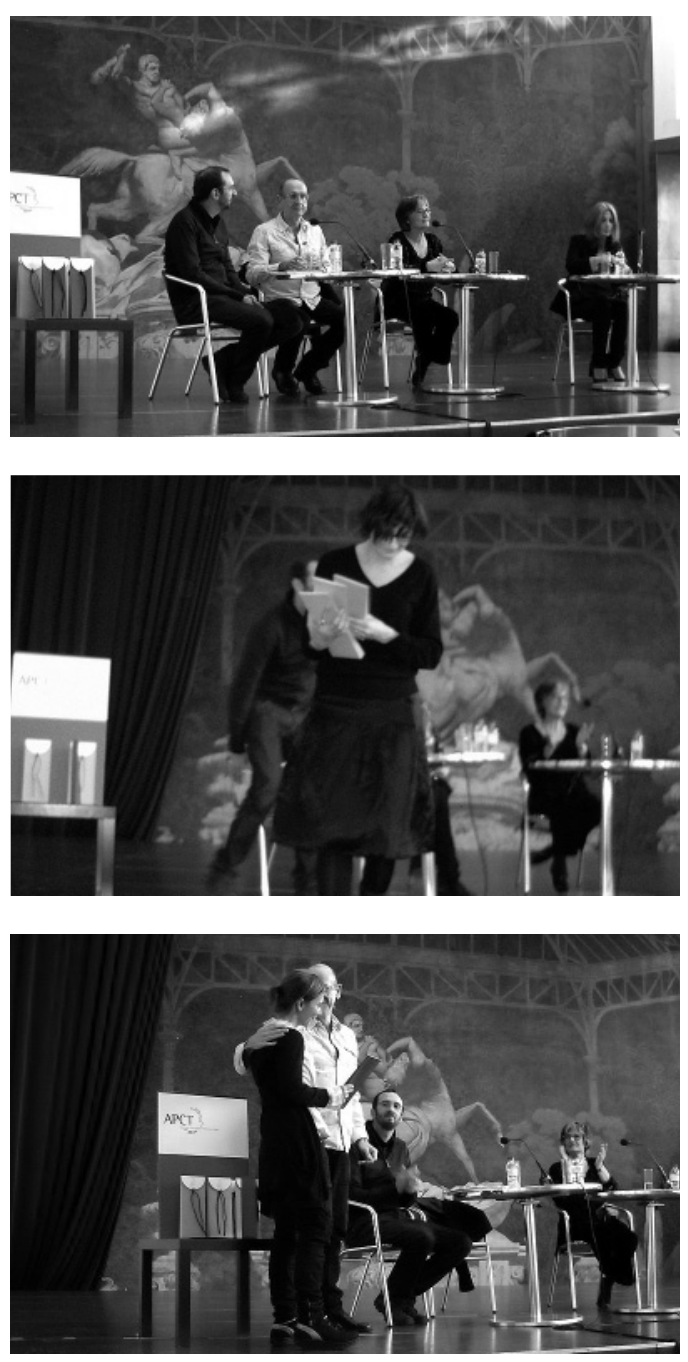

Pedro à Fábrica da Rua da Alegria", esta singular mostra incluiu grupos e companhias como: Teatro Experimental do Porto, Teatro de Marionetas do Porto, Assédio, Ensemble, Circolando, Visões Úteis, As Boas Raparigas (Vão Para 0 Céu E As Más Vão Para Todo 0 Lado), Teatro do Bolhão, Teatro de Ferro, Teatro Meia Volta e Depois À Esquerda Quando Eu Disser, Teatro do Frio, Utópolis, De Diz que Diz, De S.O.S., Palmilha Dentada, Erva Daninha, Radar 360, Tenda de Saia, Pele, Noise 'R' Us.

$\mathrm{Na}$ festa que significou esta explosão do Norte em Lisboa estiveram também envolvidos os críticos da APCT que puderam publicamente conversar com alguns dos protagonistas deste teatro. Passaram, assim, pelo Jardim de Inverno, em conversa animada com críticos da APCT, Mário Moutinho, Paula Braga, Igor Gandra, André Braga, Isabel Barros, Ada Pereira da Silva, Regina Guimarães, Saguenail e João Alpoim Botelho, entre outros. E, pelas conversas havidas, neste Ciclo e nos Encontros (atrás referidos), perpassou a ideia de que não haverá falta de projectos de qualidade; não haverá falta de criativos, encenadores, actores ou dramaturgos; não haverá falta de saber, de capacidade de gestão, ou de gosto pela actividade...

Pudesse o teatro estar mais presente nos meios de comunicação, mais activo nas escolas, mais acarinhado pelos poderes (públicos e privados), mais presente no quotidiano dos portugueses. Razões não faltam, afinal! 